\title{
LA FIESTA
}

\section{THE PARTY}

\section{AUTORES}

Benjamín Hernández Blázquez: Catedrático de la Escuela Universitaria de Estadística de la Universidad Complutense de Madrid. benjamín.hernandez@mixmail.com

\section{CURRÍCULUM VITAE}

Catedrático de la Escuela Universitaria de Estadística de la Universidad Complutense de Madrid.

\section{RESUMEN}

Proviene del latín festa, emparentado con feria, con el sentido de alegría y regocijo. De la misma raíz son festín, festivo y festival entre otras muchas; según Corominas, se documenta en castellano a principios del siglo XIII. En casi todos los idiomas modernos europeos, su grafía y contenido semántico apenas ha sufrido variación. El Diccionario de la Lengua Española describe sus definiciones, todas con idéntico significado al referido, pero a lo largo del tiempo han dado lugar a múltiples expresiones como: Fiesta de guardar, fiesta de consejo, de precepto, de cabañuelas, reales, de armas, nacional, etc.; asimismo se han conformado acepciones, como celebrar las fiestas, santificar las fiestas, aguar la fiesta o tengamos la fiesta en paz. 


\section{PALABRAS CLAVE}

Fiesta - Festival - Celebración

\section{ABSTRACT}

Comes from the Latin festa, related to fair, with the sense of joy and rejoicing. From the same root are feast, festive, festival and many others, according Corominas, Castilian is documented in the early thirteenth century. In almost all modern European languages, the spelling and semantic content has barely change. The Spanish Language Dictionary describes their definitions, all with identical meaning to the referral, but over time have resulted in many expressions such as: Party store, party advice, precept, cabañuelas, real weapons, national, etc..; also have settled meanings, and celebrate the holidays, sanctifying the holidays, we spoil the party or the party alone.

\section{KEY WORDS}

Party - Festival - Celebration

\section{ÍNDICE}

1. Concepto

2. Tipos de Fiesta

3. Carácter Antropológico de la Fiesta

4. Evolución cronológica de las Fiestas 
"La fiesta es una de las formas elementales de la vida colectiva, la expresión significativa de una solidaridad mecánica" (Durkheim).

\section{Concepto}

Proviene del latín festa, emparentado con feria, con el sentido de alegría y regocijo. De la misma raíz son festín, festivo y festival entre otras muchas; según Corominas, se documenta en castellano a principios del siglo XIII. En casi todos los idiomas modernos europeos, su grafía y contenido semántico apenas ha sufrido variación.

El Diccionario de la Lengua Española describe sus definiciones, todas con idéntico significado al referido, pero a lo largo del tiempo han dado lugar a múltiples expresiones como: Fiesta de guardar, fiesta de consejo, de precepto, de cabañuelas, reales, de armas, nacional, etc.; asimismo se han conformado acepciones, como celebrar las fiestas, santificar las fiestas, aguar la fiesta o tengamos la fiesta en paz..

De cualquier forma, la fiesta está anclada en el deseo humano de romper con las normas cotidianas, y su dimensión social susceptible de encajar en cualquier colectivo. Se puede considerar como la agregación de acciones de un grupo que adquiere forma exterior en tradiciones, costumbres y ceremonias, caracterizadas todas ellas por un elevado nivel de aceptación participativa. En la fiesta, consecuentemente, se transmiten numerosos significados: social, político, religioso... en los que la diversión desenfrenada e incluso orgiástica converge y se mezcla con la religiosa para, en simbiosis, cumplir diversas funciones como son la solidaridad y cohesión. Al respecto el etnólogo Luis Maldonado glosó que, "no existe verdadera festividad sin apertura a lo religioso, como no hay religiosidad sin una explosión a lo festivo". 


\section{Tipos de fiesta}

Resulta arduo establecer una clasificación de las numerosas fiestas españolas; tal vez el contenido del concepto podría ayudar a tipificar sus apartados; pero en cualquier caso siempre hay alguna fiesta que se escabulle a toda posible tipificación. Así lo entienden los estudiosos del tema, Caro Baroja los divide de acuerdo con las estaciones astronómicas: fiestas de invierno, de primavera y fiestas de verano y otoño. Otros sociólogos y etnólogos buscan los motivos principales que deben tenerse en cuenta (G. Atienza): según el instante iniciático, según los tiempos propicios, según la memoria que se conserva....

Este tema tan abierto y complejo precisa tener en cuenta que la distribución de las fiestas como cualquiera otra de la sociedad, dista mucho de ser uniforme ya que, entre el solsticio de verano y el doce de octubre, más del $80 \%$ de los municipios españoles celebran fiestas patronales siendo relevante la casi ausencia total, en meses como diciembre y febrero. Teniendo en cuenta lo expuesto, las fiestas pueden clasificarse en:

A) Fiestas sociales: Son las patronales, ya sean religiosas o profanas, y las conmemorativas

B) Fiestas de la naturaleza: agrícolas, estacionales y mitológicas

C) Fiestas familiares y locales de menor trascendencia, pero genuinas y específicas de cada lugar, e irrepetibles fuera de su contexto 


\section{Carácter antropológico de la fiesta}

Básicamente dos rasgos configuran, en este sentido, la fiesta: 1) ruptura con lo cotidiano, es decir, hábitos, organización social y tabúes; 2) la liberación explosiva de los instintos, aspiraciones y sentimientos. La idea de ruptura, de conculcación de normas es indisociable de la fiesta, Freud decía: "la fiesta es un exceso tolerado e incluso ordenado", "es la violación solemne de una prohibición". En este sentido implica la anulación momentánea del tiempo social que regula la vida del grupo y de ahí que posea un tiempo propio, un tiempo místico e intemporal, el tiempo de la libertad creadora.

Destacan, asimismo, los antropólogos que el desorden transgresor y la exaltación lúdica y diomisiaca, alcanza su cota mas alta en las sociedades primitivas. Como contrapartida, señalan la degradación de las fiestas en las sociedades industriales y consumistas. En este tipo de sociedades se integran todas las manifestaciones de la vida colectiva en un circuito de producción/consumo y se deterioran las relaciones interpersonales así como la potenciación de los instintos individuales de posesión y ostentación. Y, si a veces se habla de civilización del ocio, también en ella la fiesta queda inscrita en una organización y comercialización del tiempo libre que la priva de sus valores propios.

El tiempo libre, por definición, debería ser el tiempo de libre elección y sin consejeros de ningún tipo. Es o puede ser, una revolución; una gran transformación humana se inició cuando los hombres empezaron a luchar no solamente por salarios en dinero, sino por salarios en tiempo. Extrapolando hacia la fiesta, se habla en este sentido de la pérdida del sentido de lo gratuito y de la capacidad de comunicar con otros. En estas coordenadas, tiende a ser tan sólo la ocasión del consumo en solitario, de uno u otro espectáculo, en el que uno no es actor ni compromete su propia intimidad, en vez de implicar una auténtica comunión con los otros, es decir, una espontánea 
participación en lo colectivo. Y ni siquiera la escasez de formas bajo las que parece sobrevivir esa imagen de la fiesta colectiva, se escurre de la dinámica sociedad de consumo, que las organiza y comercializa de acuerdo con su previsible rentabilidad.

\section{Evolución cronológica de las fiestas}

La sociedad española tuvo siempre un gran sentido de la alegría que supo plasmar en numerosos festejos, religiosos y profanos; y en ocasiones una y otra cosa juntas, con los que generó un calendario lúcido a lo largo de todo el año.

Actualmente existen en el mundo varias decenas de calendarios que miden el tiempo a la vez que organizan las fiestas de modo distinto; pero casi todos recopilan, además del santoral, las efemérides y datos civiles diversos. El calendario sirve para distribuir el tiempo de trabajo y de ocio y, aquí las fiestas se sincronizan de acuerdo con un ciclo anual formando un sistema continuo de ordenación cronológica.

Aunque los calendarios maya, egipcio, musulmán ... tendían a ser herméticos, por sus poros han salido influencias que cristalizaron en fiestas del mundo occidental, y también en sentido sincrético que hace que muchas fiestas mezclen elementos procedentes del ciclo lunar y solar confundiéndose el año litúrgico con el ciclo agrícola, como aconteció con los celtas y romanos.

Por esta serie de eventos causales, las fiestas del solar español han pasado por diversos hitos o eslabones. Cuando Augusto se inició como emperador en Roma, el recién nacido calendario juliano tenía 76 días festivos, pero cinco siglos después, próximos a la caída del imperio, la depravada sociedad romana llegó a contabilizar hasta 171 fiestas entre circo, juegos, ferias... 
Con la llegada del cristianismo, se dedicó el primer día de la semana al culto divino, era el "dies dominica" o día del señor; como fiestas anuales se instauraron la Pascua y Pentecostés, ambas de raigambre judía. La primera conmemoraba el hecho fundamental, la muerte y resurrección de la esencia del cristianismo, y Pentecostés evocaba la venida del Espíritu Santo sobre los apóstoles. Ambas fiestas son de origen apostólico y durante algún tiempo, fueron las únicas celebradas por los cristianos. La tercera que se añadió fue la Epifanía o manifestación del Señor a los gentiles, que figuró antes en las iglesias orientales.

Polémica fue la festividad de la Pascua que era distinta para las iglesias de oriente, por lo que el sínodo de Arlés y posteriormente el concilio de Nicea, año 325, decretaron que "la Pascua cristiana tuviera lugar el primer domingo después de la primera luna llena del equinoccio de primavera, y el domingo de Carnaval se situaría siete semanas antes de esta fecha".

Sucesivamente, la Iglesia impulsó el año eclesiástico haciendo que las fiestas fueran más solemnes, así nacieron la Circuncisión del Señor (1 de enero) y la Invención de la Santa Cruz (3 de mayo). El esplendor del culto medieval generó la festividad del Corpus, celebrándose por primera vez en Lieja (1246).

Por otra parte, las fiestas dedicadas a la Virgen fueron en aumento tras el concilio de Efeso (siglo V) y por las nuevas ordenes mendicantes. A estas fiestas añadieron los cristianos otras muchas dedicadas a mártires y santos: san Esteban, san Lorenzo y san Martín, y su veneración dio origen a la literatura hagiográfica; se aumentaron las actas de los mártires, algunas sin rigor histórico pero que gestaron los Martirologios (Sinaxarios en oriente) que eran listas de los santos mas venerados con la indicación de la fecha de su muerte o martirio. Ya en el S. XVII, aunque tratado en el largo concilio de Trento, las fiestas de precepto se habían disparado en número, como en la antigua Roma, pues los obispos tenían facultad de prescribirlas en sus diócesis 
respectivas. Por eso, el papa Urbano VIII en el año 1642, Bula Universa, redujo "a 34 las fiestas mayores, fuera de los domingos".

Después de Urbano VIII hubo otro recorte, dado que en algunas ciudades el número de días festivos casi se equiparaba con los no festivos, esta "poda" la llevó a cabo el papa Pio X (1911) "para favorecer a las clases mas pobres".

Antes, el calendario español (1910) señalaba 40 días de fiestas de guardar, que además de las clásicas figuraban, entre otros: san Joaquín, san Isidro, Miércoles de Ceniza y los días del cumpleaños del rey, de la reina así como de su matrimonio. Además, en el sector rural, se contaba con las festividades de sus santos devotos y milagreros: san Blas, san Antonio, san Roque, etc.; con la llegada de la República (1931) se suprimieron las celebraciones reales, instaurándose otras alusivas; como el gobierno de Franco lo hizo con el 18 de julio.

La reforma fue concluida con el Concilio Vaticano II que elaboró unas "Normas generales sobre el Año Litúrgico" que ordenaban que los santos de importancia universal se celebraran en toda la Iglesia; los otros, inscritos o no en el calendario, quedaban a la discrecionalidad del lugar.

Necesariamente, estas "normas", provocaron un movimiento en el calendario hasta entonces vigente que se manifestó finalmente en la desaparición de unas fiestas y el desplazamiento de otras. Respecto a las primeras, hacia referencia a las conmemoraciones sobre las que los hagiógrafos no habían constatado noticias históricas significativas y, aunque provocaron la ira general en alguna localidad, fueron barridas del almanaque festivo; así bajaron de su pedestal, como santos de raigambre universal: san Cristobal, santa Bárbara, santa Catalina, etc., así hasta 25 festividades cuyos santos respectivos fueron "degradados". Respecto del desplazamiento santoral, esto acaeció a otros tres de "importancia general", dado que 
sus onomásticas caían en tiempo de cuaresma: fueron san Gregorio Magno (pasó del 12 de marzo al 3 de agosto), santo Tomas de Aquino (del 7 de marzo al 28 de enero) y san Benito (21 marzo al 11 julio).

Finalmente, en los pueblos españoles que bailan al compás de las estaciones del año, las fiestas cambian pero siguen y actúan en simbiosis con el tejido social más ancestral; cambian las fiestas, porque cambia la gente, no porque en los lugares se vayan los de aquí o retornen los de allá, cambian como han cambiado las costumbres. En el devenir de la historia, las fiestas y tradiciones también permanecerán en este milenio, aunque cambiando, como así lo han hecho, desde que los pueblos empezaron a evolucionar; $y$, en el futuro, puede que sea tradición lo que hoy se nos antoja novedoso. 